\title{
Competition for hydrogen between acetogenic bacteria and methanogenic archaea
}

\author{
B Morvan, G Fonty \\ INRA, Laboratoire de Microbiologie, C.R. de Clermont-Ferrand-Theix \\ 63122 Saint Genès Champanelle, France
}

Hydrogen is an important intermediate in the microbial anaerobic degradation of organic matter. In the rumen, hydrogen produced by hydrolytic and fermentative microorganisms could be re-utilized by three bacterial groups: the methanogenic archaea, the sulfatereducing bacteria and the acetogenic bacteria. Methanogens are the main hydrogenotrophic population in the rumen whereas acetogens are present in low numbers contrary to other digestive ecosystems such as the gut of xylophagus termites (Breznak and Switzer, 1986, Appl Environ Microbiol, 52, 623-630) or colon of non-methanogenic human subjects (Doré et al, 1995, FEMS Microbiol. Ecol, in press). Acetogens are known to have a $\mathrm{H}_{2^{-}}$ treshold and a $\triangle \mathrm{G}$ 'o higher than methanogens (Cord-Ruwish et al, 1986, Arch Microbiol, 149, $350-357$ ). This work was undertaken to study the competition for $\mathrm{H}_{2}$ between a methanogen and two acetogenic strains, in vitro.

Methanogenic strain MFC was isolated from the caecum of a horse and the two acetogens Ser5 and Ser8 were isolated from the rumen of a $20 \mathrm{~h}$-old lamb. Strains were precultivated on the AC-11 medium (Breznak and Switzer, 1986) under $\mathrm{H}_{2} / \mathrm{CO}_{2}$ at $39^{\circ} \mathrm{C}$. Fourty-eight-hour-old cultures were used to inoculated AC-11 medium with a similar number of acetogenic and methanogenic cells. Pure cultures of each microorganism were performed as control. Tubes were pressurized with $\mathrm{H}_{2} / \mathrm{CO}_{2}(80: 20)$ and incubated under shaking at $39^{\circ} \mathrm{C}$. After 3 days of incubation, $\mathrm{H}_{2}$ consumed and $\mathrm{CH}_{4}$ produced were analyzed by gas chromatography and acetate produced was measured by enzymatic assay.

In presence of Ser5, $\mathrm{CH}_{4}$ production by MFC decreased from $347 \mu \mathrm{mol}$ in pure culture to $228 \mu \mathrm{mol}$ for the same quantity of $\mathrm{H}_{2}$ used whereas in presence of Ser8 the decrease of $\mathrm{CH}_{4}$ production was not significatively different (347 vs 337). Acetate produced by Ser5 in the coculture with MFC was lower than in pure culture $(225 \mu \mathrm{mol} v \mathrm{~s} 138 \mu \mathrm{mol})$. Acetate production by Ser 8 in coculture with MFC was severely decreased (136 vs $19 \mu \mathrm{mol}$, respectively). These findings show that some acetogenic strains are able to compete with methanogens for $\mathrm{H}_{2}$, in vitro. The reduction of methanogenesis in profit of acetogenesis would be benificial for animal (decrease of energy loss) and for environment (decrease of $\mathrm{CH}_{4}$ release). At present, we test the competition between acetogens and methanogens in vivo in the rumen of gnotobiotically-reared lambs. 